\title{
Mestrados e doutorados profissionais como espaços de formação docente
}

\author{
Luiz de Sousa Junior \& Robert Evan Verhine
}

\begin{abstract}
Resumo
Este artigo aborda o papel dos programas profissionais de pós-graduação em Educação no Brasil como lócus de formação docente. Parte-se do pressuposto de que tais programas, considerando sua missão precípua de formar pesquisadores de alto nível e de, em seu trabalho final, apresentar produtos e serviços inovadores que contribuam para o aprimoramento do fazer pedagógico, possam suprir uma lacuna, existente no Brasil, de maior interação do ensino superior com a educação básica. A identidade dos programas profissionais, todavia, encontra-se, ainda, em construção. Com apoio na abordagem qualitativa, de natureza bibliográfica e documental, o presente artigo contextualiza o surgimento dos programas profissionais e analisa experiências de intervenção. Concluindo, afirma que a introdução de programas profissionais de educação, ainda recente, pode se constituir em um movimento importante para a redução de assimetrias presentes na oferta de pós-graduação no país e para o desenvolvimento de conhecimentos teóricos e técnicos necessários à solução de problemas concretos enfrentados pelos docentes e demais profissionais da educação básica em seu cotidiano escolar.
\end{abstract}

Palavras-chave:

educação; pós-graduação profissional; formação docente. 


\title{
Professional masters and doctorates as the locus of teacher preparation
}

\begin{abstract}
This article addresses the role of professional graduate programs in Education in Brazil as the locus of teacher preparation. The study is based on the premise that these programs, considering their mission to prepare high level researchers who, in their final outputs, present innovative products and services that contribute to the improvement of pedagogical efforts, are able to overcome the gap the currently exists in Brazil between higher and basic education. The identities of the professional programs, however, are still in a process of construction. The article is based on a qualitative study, of a bibliographical and documental nature, that contextualizes the rise of professional programs and analyzes their experiences with social intervention. The study concludes by affirming that the introduction of professional programs in Education, although recent, can constitute an important movement to reduce the asymmetries that characterize graduate education in the country and to develop the theoretical and technical knowledge necessary for the solution of concrete problems that are confronted within schools on daily basis by teachers and other professional personnel.
\end{abstract}

Key Words: education; professional graduate study; teacher preparation

\section{Master et doctorats professionnels en tant qu'espaces de formation du corps enseignant}

Resumé : Cet article aborde le rôle des programmes professionnels de troisième cycle dans l'éducation au Brésil comme locus de la formation du corps enseignant. L'étude part de l'hypothèse où de tels programmes, considérant leur mission primordiale de former des chercheurs de haut niveau et de, dans leurs travaux finaux, présenter des produits et services innovants qui contribuent à l'amélioration des pratiques pédagogiques, peut combler des lacunes présentes au Brésil de plus forte interaction de l'enseignement supérieur avec l'éducation de base. L'identité des programmes professionnels, toutefois, se trouve toujours en construction. II s'agit d'une étude d'abordage qualitatif, de nature bibliographique et documentée, qui contextualise l'apparition des programmes professionnels et analyse les expériences d'intervention. Cette étude conclut affirmant que l'introduction de programmes professionnels d'éducation, encore récente, peut se constituer dans un mouvement important pour la réduction des asymétries présentées dans l'offre de troisième cycle dans le pays et pour le développement de connaissances théoriques et techniques nécessaires pour la solution de problèmes concrets rencontrés par les enseignants et d'autres professionnels de l'éducation de base dans leur quotidien scolaire.

Mots clés: éducation; troisième cycle professionnel; formation du corps enseignant.

\section{Maestrías y doctorados profesionales como espacios para la formación del profesorado.}

Resumen: Este artículo discute el papel de los programas profesionales de posgrado en educación en Brasil como locus para la formación docente. El estudio supone que tales programas, considerando su misión principal de capacitar a investigadores de alto nivel y, en su trabajo final, presentar productos y servicios innovadores que contribuyan a la mejora de la práctica pedagógica, pueden llenar un vacío en Brasil. Mayor interacción de la educación superior con la educación básica. La identidad de los programas profesionales, sin embargo, todavía está en construcción. Este es un estudio cualitativo, bibliográfico y documental, que contextualiza el surgimiento de programas profesionales y analiza las experiencias de intervención. Este estudio concluye afirmando que la introducción de programas de educación profesional, aún recientes, puede constituir un movimiento importante para reducir las asimetrías presentes en la oferta de posgrado en el país y desarrollar el conocimiento teórico y técnico necesario para la solución de problemas concretos que enfrentan los docentes y otros profesionales de la educación básica en su vida escolar diaria.

Palabras clave: educación; posgrado profesional; formación docente. 


\section{Introdução}

Dados da Unesco (2016) apontam para uma exclusão escolar de cerca de 263 miIhões de crianças e jovens em todo o globo. É um número assustador. Nesses dados, estão inclusos 25 milhões de crianças em idade escolar própria do ensino primário ${ }^{1}$ que não terão a oportunidade de acessar a sala de aula. Por outro lado, dos jovens que conseguem concluir o ensino médio, apenas 14\% são provenientes de países com baixa renda.

Mudar esse quadro exige, obviamente, um esforço hercúleo dos países que enfrentam essas graves distorções educacionais e, sobretudo, uma mudança de orientação no que diz respeito aos profissionais responsáveis pela educação das crianças, jovens e adolescentes: o corpo docente. Para se enxergar a dimensão dos desafios dessa empreitada, pode-se começar pensando acerca da necessidade quantitativa de docentes nos próximos 10/15 anos. Ainda com base no estudo da Unesco, estima-se que, até 2030, os países devem recrutar um total de 68,8 milhões de professores, dos quais 24,4 milhões atuarão no ensino primário e 44,4 milhões, no ensino secundário.

Para além da demanda expressiva de professores nos próximos anos, há de se destacar a qualidade desses profissionais, tanto no que diz respeito à formação - seja inicial, continuada, seja de treinamento e requalificação - quanto à remuneração condigna e atrativa frente aos enormes desafios que se apresentam. A formação docente e a valorização do magistério, aliadas a outros fatores, são elementos importantes na promoção da melhoria da qualidade da educação, o chamado "efeito professor". Assim, quanto maior o nível de formação, experiência e motivação do docente, melhor o resultado do desempenho dos alunos (Soares, 2005).

No Brasil, o percentual de professores com formação de nível superior, concluída ou em andamento, atuando nos anos iniciais do ensino fundamental, no ano de 2013, era de $77,2 \%$. Desses docentes, um quantitativo significante exerce suas atividades sem a formação específica, particularmente em áreas como Matemática, Física, Química e Biologia. A situação se agrava quando se trata de professores de educação básica que cursaram alguma pós-graduação. Nesse estrato de formação, apenas 30,2\% com exercício na educação básica conseguiram cursar algum tipo de estudo de pós-graduação. Portanto, urge que sejam ensaiadas e implementadas novas estratégias de políticas de formação docente no ensino superior, tendo em vista um enorme percurso para se garantir, a todos os professores da educação básica, uma formação compatível com a sua área específica de atuação profissional, bem como o aprofundamento dos estudos em nível de pós-graduação.

Este artigo visa, portanto, problematizar o papel dos programas de pós-graduação de caráter profissional da área de Educação ${ }^{2}$ na formação dos professores e na melhoria da qualidade do trabalho docente. Assim, procura responder à seguinte pergunta: 
os programas profissionais da área de Educação podem se constituir numa alternativa de aprimoramento da formação docente com forte impacto na qualidade da educação?

Partimos da premissa de que os programas profissionais, por seu caráter inovador e de intervenção na realidade escolar, a partir dos produtos obtidos em razão da pesquisa e da reflexão do próprio fazer docente, podem, com efeito, cumprir relevante papel quanto à melhoria da qualidade da educação básica no Brasil, o que justificaria o interesse público na sua oferta e expansão.

\section{Formação dos Professores e o Papel da Pós-Graduação no Brasil}

A formação de professores no Brasil tem um histórico de descontinuidade e, mesmo, ausência de políticas consistentes, desde a colonização até os dias atuais. Logo, as políticas de formação docente, quase sempre fragmentárias, buscaram responder a "pressões imediatistas, a alguns movimentos sociais emergentes, e, particularmente, dos que tinham 'voz' ou alguma função de poder e influência em dado momento" (Gatti et al, 2019, pp. 31-32).

Cabe questionar, inicialmente, qual a essência do trabalho docente. A resposta, ainda que pareça simples à primeira vista, remete-nos à discussão do trabalho enquanto categoria ontológica da condição humana. Com efeito, se é pelo trabalho que nos tornamos humanos, é pelo trabalho pedagógico que nos tornamos professores. Logo, o trabalho pedagógico constitui a razão de ser da atividade docente.

Dessa assertiva deriva a compreensão de que a simples transmissão de conhecimento, por si só, não caracteriza o fazer docente. Há que se dominar técnicas pedagógicas, pautadas em fundamentos filosófico-sociais e histórico-psicológicos, que otimizem o processo de repasse do conhecimento historicamente acumulado pela sociedade às gerações futuras. Essas técnicas serão tão mais eficientes para os fins propostos quanto maior for o domínio dos conteúdos a serem transmitidos. Portanto, a dicotomia conteúdo-técnica, ainda que mobilize calorosos debates, é meramente esquemática do ponto de vista da concretude do trabalho em sala de aula, ${ }^{3}$ vale dizer, do fazer pedagógico, visto que ambos constituem uma unidade indissolúvel da organização do trabalho docente. Em consequência, o processo de formação de professores/as assume contornos específicos da formação em nível superior, exigindo, dessa maneira, agências únicas e especializadas quanto ao exame teórico-conceitual das bases epistemológicas e de prática pedagógica dos profissionais do magistério.

No Brasil, desde a colonização, diversas agências foram concebidas como lócus de formação docente. Podemos destacar os institutos de Educação, as escolas normais, as faculdades de Educação, as faculdades isoladas, dentre tantas outras. A despeito de essas instâncias se expandirem, sobretudo, pela via privada, não houve, 
até os anos de 1990, uma política eficaz de formação docente, em contraste com as enormes demandas de escolarização e de busca da qualidade da educação básica.

O ponto de inflexão se deu na década de 1990, a partir da redemocratização do país e após mais de vinte anos sob o domínio dos militares, sobretudo com a aprovação da Lei de Diretrizes e bases da Educação Nacional - LDBEN (Lei n.394/96). Resultou daí uma série de legislações ordinárias que buscaram suprir a lacuna no normativo jurídico-institucional a partir de uma perspectiva democrática. Desse modo, o Brasil chega ao final da segunda década do século XXI com relativo avanço no que diz respeito às agências de formação, porém com profundos questionamentos acerca da qualidade e da eficácia dos seus propósitos.

A pós-graduação no Brasil, por sua vez, embora bastante recente, apresentou, sobretudo nos últimos anos, muitos avanços e, também, limitações alusivas ao crescimento e à relação com o mundo do trabalho. Evidentemente, essa expansão obedeceu às condições particulares de cada área de conhecimento. Em termos gerais, a evolução dos cursos de pós-graduação no Brasil, a partir de 1976, apresentou a seguinte performance:

Tabela 1 - Evolução dos cursos de pós-graduação no Brasil (1976 - 2016)

\begin{tabular}{ccccc}
\hline ANO & Doutorado & Mestrado & $\begin{array}{c}\text { Mestrado } \\
\text { profissional }\end{array}$ & Total geral \\
\hline 1976 & 181 & 518 & 0 & 699 \\
1980 & 260 & 680 & 0 & 940 \\
1985 & 332 & 784 & 0 & 1116 \\
1990 & 469 & 993 & 0 & 1462 \\
1995 & 682 & 1289 & 0 & 1971 \\
2000 & 903 & 1620 & 98 & 2621 \\
2005 & 1099 & 1923 & 202 & 3224 \\
2010 & 1630 & 2771 & 356 & 4757 \\
2016 & 2186 & 3398 & 741 & 6325 \\
\hline
\end{tabular}

Fonte: Nobre e Freitas, 2017, p. 32.

A despeito de todas as desconfianças atinentes ao suposto caráter produtivista do modelo de pós-graduação adotado no Brasil, com métricas ancoradas em scores quantitativos, é fato que o Sistema Nacional de Pós-Graduação (SNPG), sob o 
comando da Coordenação de Aperfeiçoamento de Pessoal de Nível Superior (CAPES), ${ }^{4}$ encontra-se consolidado e vem se mostrando atento às críticas com mudanças, em seu sistema de avaliação, que incorporam tendências mais qualitativas, como a autoavaliação, embora sem desprezar as métricas quantitativas, sobretudo no que diz respeito ao impacto da produção intelectual.

Deve-se destacar o enfoque dado à formação dos professores da educação básica na reformulação da CAPES em 2007, uma vez que tal atribuição foi consolidada dois anos depois através do Decreto n 6755, de 29 de janeiro de 2009, que instituiu a Política Nacional de Formação de Profissionais do Magistério da Educação Básica. ${ }^{5}$ Logo em seguida, por meio da Portaria $n^{\circ} 7$, de junho de 2009, foi regulada a oferta de programas de mestrado profissional no âmbito da CAPES.

Pretendia-se, com essa política, aprimorar a qualidade da educação básica do sistema de ensino do Brasil, estimulando experiências inovadoras e aguçando o interesse nos níveis ulteriores de ensino. Com isso, prenunciava-se uma maior integração da pós-graduação com a educação básica.

\section{Breve Diagnóstico da Pós-Graduação em Educação no Brasil}

Embora recente, a pós-graduação no Brasil encontra-se relativamente consolidada. A política de avaliação dos programas e cursos, como veremos mais adiante, assegurou uma qualidade do sistema com base em parâmetros internacionais, embora algumas áreas tenham se destacado mais do que outras. A expansão quantitativa se deu a partir, como não poderia deixar de ser, de programas acadêmicos, isto é, aqueles destinados à formação de pesquisadores e de quadros do ensino superior. Mais recentemente, foram implantados os mestrados profissionais, programas com perfil voltado para o aperfeiçoamento de profissionais que já atuam no mercado de trabalho seja público, seja privado, dando início, assim, a um novo ciclo de expansão que, ao que tudo indica, ainda está longe de se esgotar.

O Parecer n 977/1965, conhecido como Parecer Sucupira, ${ }^{6}$ que regulamentou a pós-graduação brasileira, já introduzira a pós-graduação profissional stricto sensu (mestrado e doutorado), prevendo programas profissionais. Todavia, somente em 1998, a CAPES dispôs sobre o reconhecimento dessa modalidade de pós-graduação. Desse modo, a Portaria n 80/1998 demarcou o reconhecimento dos mestrados profissionais. Posteriormente, como se viu anteriormente, o Ministério da Educação regulamentou de maneira mais precisa a oferta dos MPs.

No caso específico da área de Educação, os primeiros programas de mestrado profissional só vieram a ser instalados a partir de 2010.7 A expansão do conjunto de programas, desde a avaliação trienal de 2007 até o ano de 2019, apresentou o comportamento exposto no gráfico abaixo. 


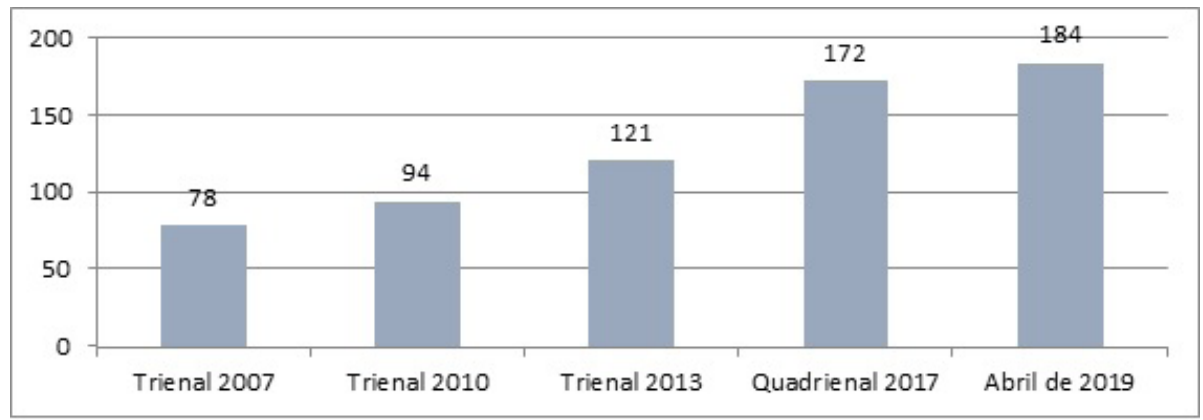

Gráfico 1 - Evolução recente dos Programas de Pós-Graduação da área de Educação (2007 - 2019)

Fonte: Documento de área da educação da CAPES, 2019.

Verifica-se, pois, que o crescimento no número total de programas da área de Educação apresentou um percentual expressivo de 136\% em apenas 12 anos, ou seja, mais do que dobrou nesse pequeno espaço de tempo. Contudo essa expansão quantitativa se deu de forma mais abrupta no período de 2013 a 2017, saltando de 121 programas para 172, ou seja, 42\%. Posteriormente a esse período, o crescimento foi de apenas $7 \%$, indicando, aparentemente, um certo arrefecimento na expansão dos cursos de pós-graduação em Educação. Desagregando os dados entre as modalidades (acadêmico e profissional), observamos que o salto verificado entre 2013 e 2017 deve-se ao incremento dos mestrados profissionais, conforme se visualiza no gráfico que se segue.

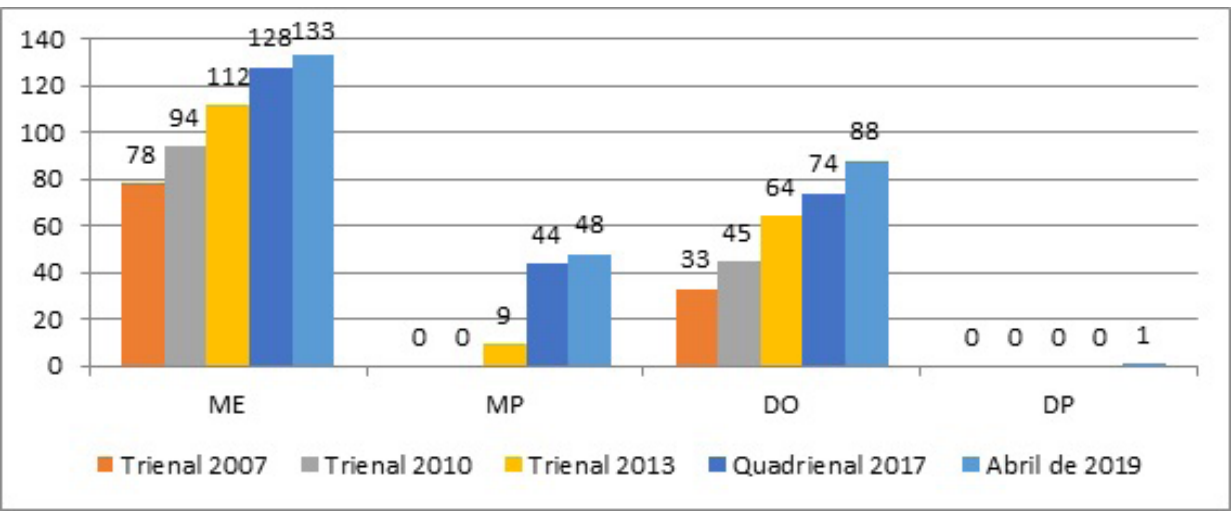

Gráfico 2 - Evolução dos Programas de Pós-Graduação da área de Educação, por nível e modalidade (2007 - 2019). Fonte: Documento de área da educação da CAPES, 2019. OBS: ME - mestrados acadêmicos; MP - mestrados profissionais; DO - doutorados acadêmicos; DP: doutorados profissionais. 
Como dito anteriormente, os Mestrados Profissionais em Educação (MPE), no Brasil, foram instalados a partir de 2010. Na avaliação trienal de 2013, foram avaliados os primeiros MPEs, no total de nove cursos. No início do ano de 2019, esse número saltou para 48 cursos. Portanto, em pouco mais de uma década, houve um expressivo crescimento na ordem de 433\%. Um dado extremamente importante diz respeito ao fato de que, no final de 2018, foi aprovado o primeiro doutorado profissional, iniciando-se uma nova etapa quanto aos programas profissionais. Em termos proporcionais, quando comparado ao conjunto dos cursos de pós-graduação da área de Educação, a participação dos mestrados profissionais em relação aos acadêmicos saltou de cerca de 7,4\%, na trienal de 2013, para 26,5\% em 2019.

Também é importante ressaltar que a ampliação da pós-graduação da área de Educação se deu mais fortemente em instituições públicas. Em 2007, estas respondiam por 59\% da totalidade dos cursos, tendo este número alcançado 69\% em 2019.

\section{O Sistema de Avaliação da CAPES e a Identidade dos Mestrados Profissionais}

A CAPES, ao longo dos anos, foi arquitetando uma robusto sistema de avaliação dos cursos de pós-graduação no Brasil. Embora divergências aflorem quanto à modelagem adotada, sobretudo nos colégios de ciências da vida e ciências exatas, tecnológicas e multidisciplinar, ${ }^{8}$ claramente inspirada em padrões internacionais de matriz quantitativista, com ênfase na produção de artigos em periódicos e fator de impactos das revistas e dos artigos, o colégio de humanidades, da qual faz parte a área de Educação, vem mesclando abordagem qualitativa e quantitativa nas avaliações dos programas. O olhar, porém, dessas avaliações parte do ponto de vista dos programas acadêmicos. Assim, os mestrados profissionais vinham sendo avaliados, via de regra, pelos mesmos procedimentos dos programas acadêmicos, sem considerar suas especificidades.

É evidente que existem aproximações entre os programas acadêmicos e os profissionais, na medida em que ambos têm a função precípua de formar quadros de pesquisadores de alto nível para intervenção na educação básica e na superior. Mas também é verdade que existem diferenças significativas entre essas modalidades, sobretudo pelo fato de os programas profissionais terem como objetivo central desenvolver produtos que sirvam, ou pelo menos sinalizem na direção, para a solução de problemas concretos vivenciados no ambiente em que o profissional da educação está inserido. Mesmo que tal identidade ainda esteja em construção, parece não haver outro caminho para a consolidação dos MPE.

Esses programas, ainda não instituídos por completo, em razão de apresentar uma nova perspectiva, devem ser compreendidos com base em uma dinâmica social 
diferenciada e num cenário de debates, tensões, retrocessos, polêmicas, revisões, aprofundamentos e avanços, portanto, em construção (Fialho, Hetkowski, 2017, p. 26).

Essa preocupação tem se tornado cada vez mais ponto de diálogo e interlocução envolvendo a CAPES, as coordenações de áreas e os próprios programas profissionais. Uma iniciativa bastante eloquente acerca da mudança de percepção da CAPES sobre a avaliação dos programas profissionais foi a instituição de um Grupo de Trabalho sobre produção técnica. Executadas as atividades do grupo, publicou-se um relatório ${ }^{9}$, com a finalidade de sintetizar uma metodologia de avaliação da Produção Técnica e Tecnológica (PTT), aplicável a todas as áreas de avaliação, e propor um método de classificação e indicadores desses produtos. Na definição dos produtos técnico e tecnológico, partiu-se dos conceitos de produtos, serviços, processo/atividade, relevância/utilidade. Ao final do estudo, o GT apresentou 23 produtos, sendo que o Conselho Técnico-Científico - Ensino Superior (CTC-ES) da CAPES reduziu-os a um total de 21, a serem mensurados pelas diversas áreas nas próximas avaliações.

A área de Educação, em seu documento produzido para o ano de 2019 e subsequentes, no que diz respeito à avaliação de novos programas, sinaliza para maior pontuação aos produtos resultantes de trabalhos de conclusão dos programas profissionais designados de forma genérica de Produtos Técnicos e Tecnológicos (PTT) com ênfase em patentes, material didático-instrucional, desenvolvimento de aplicativos e de produtos, dentre outros. A adoção de pontuação para os PTTs deve contribuir para maior e melhor delimitação do escopo de atuação dos programas profissionais de educação e indução de formulação de uma identidade mais clara de intervenção social no âmbito da educação, sem desmerecer, contudo, a produção científica propriamente dita. A construção da identidade dos MPEs permitirá focar-se, mais adequadamente, a formação docente no âmbito da pós-graduação.

\section{A Formação Docente em Nível de Pós-Graduação Profissional}

Uma das questões mais debatidas atualmente no campo da educação superior e da pós-graduação tem a sido a pouca relação mantida com a educação básica, mais precisamente com o cotidiano do fazer pedagógico. Com efeito, nos programas acadêmicos, o objetivo maior tem sido a formação de pesquisadores com vistas a atuar no próprio ensino superior. A articulação com a educação básica, embora existente, ainda se dá de forma indireta, ou seja, na formação dos formadores de profissionais da educação. Nesse sentido, os programas profissionais de educação, considerando uma praxis pedagógica com ênfase em intervenção no mundo do trabalho, podem contribuir, de forma mais efetiva, na formação profissional do magistério da educação básica e, portanto, em maior articulação entre os níveis educacionais e a educação básica, devendo se constituir em dos seus mais relevantes elementos inovadores. 
A pós-graduação na modalidade profissional, enquanto etapa constitutiva do processo de profissionalização de professores e professoras da educação básica e superior, pode "colaborar para o desenvolvimento da autonomia da ação docente por meio do aprofundamento do corpo de conhecimento que Ihe é específico" (Campos; Guérios, 2017, p. 38). Não se pode perder a perspectiva de mestrado profissional forme pesquisadores que produzam ciência a partir de sua prática e apresentem postura proativa de mudança da realidade onde se inserem. Portanto, a pesquisa tem papel central na formação dos mestres profissionais em educação.

$\mathrm{Na}$ atualidade, os mestrados profissionais em educação apresentam diferentes ênfases quanto ao seu projeto pedagógico. A primeira ênfase, por parte dos programas de pós-graduação, é direcionada à formação continuada como um aprimoramento profissional dos educadores. Os programas como PROFMAT (Matemática), PROFIS (Física), PROFLETRAS (Letras), PROFARTES (Artes), PROFHISTORIA (História), PROFBIO (Biologia) foram estruturados em rede com polos em várias universidades, sendo os únicos programas na modalidade profissional apoiados financeiramente pela CAPES. Alguns desses programas - a exemplo do PROFMAT e do PROFIS - tratam a formação docente como complemento e aprofundamento de conteúdos abordados do ponto de vista formal, e não do ensino, e não contemplam disciplinas ou estudos sobre a educação. ${ }^{10}$ (Oliveira, B. J. de; Zaidan, S., 2018, pp. 41-57).

A segunda ênfase, formação para pesquisador, é aquela que predomina em mestrados acadêmicos, mas que foi incorporada também a alguns mestrados profissionais. O principal argumento para essa vertente é sua potencial contribuição para o avanço da área de conhecimento, com investigações que melhorem a compreensão dos diversos aspectos do fenômeno educacional. Há muito que se reconhece a refutação das teorias explicativas vigentes como uma das formas dessa contribuição. Ao citar como exemplos falhas nas análises ou novas chaves interpretativas, essas pesquisas trazem, de alguma forma, avanços para a área de conhecimento. A justificativa mais recorrente das pesquisas desse grupo é a lacunar, ou seja, a falta de estudos suficientes sobre um determinado aspecto. (Oliveira, Zaidan, 2018).

A terceira ênfase, na produção de conhecimento aplicado, é a que têm o foco no desenvolvimento de processos ou produtos de natureza educacional que se constitua em material que possa ser utilizado por outros profissionais na melhoria da educação. Muitos profissionais, sobretudo após anos de experiência em salas de aula, na gestão ou em processos educativos não escolares, criam procedimentos, desenvolvem atividades, metodologias de ensino e avaliação, estratégias de envolvimento das famílias, materiais e situações de aprendizagem que ficam sem registro ou raramente chegam a ser compartilhados ou replicados. (Oliveira, Zaidan, 2018).

Essa última ênfase encontra-se mais presente nos cursos de pós-graduação profissional da área de educação. Estudo realizado por Calderón e outros (2019), com 
base em levantamento realizado nas páginas eletrônicas desses quarenta e quatro cursos de MPE existentes no ano de 2018, aponta que a formação de professores constitui o principal eixo temático dos programas profissionais em educação.

Tabela 2 - Grandes Focos Temáticos dos Mestrados Profissionais em Educação no Brasil

\begin{tabular}{lcc}
\hline Grandes Focos Temáticos & Quantidade & $\mathbf{0}$ \\
\hline Formação de professores em diversas modalidades & 16 & 36,8 \\
Gestão educacional em diversas modalidades & 10 & 22,7 \\
Educação em campos específicos & 7 & 15,3 \\
Educação, tecnologias e educação a distância & 6 & 13,8 \\
Ensino-aprendizagem, currículo e práticas pedagógicas & 5 & 11,4 \\
\hline Total & $\mathbf{4 4}$ & $\mathbf{1 0 0 , 0}$
\end{tabular}

Fonte: Calderón, et al, (2019, p. 144).

Observa-se que o eixo de formação de professores constitui o principal foco temático dos MPEs. Todavia esse dado esconde, muito provavelmente, maior intervenção dos mestrados profissionais na formação docente. Com efeito, o foco temático diz respeito à chamada área de concentração dos programas. Essas áreas, em geral, são desdobradas em linhas de pesquisa. Assim, mesmo áreas como tecnologias, currículos e práticas pedagógicas podem abrigar pesquisas direcionadas à formação de professor.

Nesse sentido, o Curso de Mestrado Profissional em Educação da Universidade Federal da Bahia (UFBA), por exemplo, tem a seguinte área de concentração: Currículo, linguagens e inovações pedagógicas. Suas linhas de pesquisa se desdobram: a) Educação e linguagens; b) Currículo, ensino e escola. Essa segunda linha agrega pesquisas como: Formação de professores das comunidades quilombolas do Território do Sisal; Materiais curriculares educativos sobre matemática em ambientes virtuais e as análises dos professores; Formação em exercício de professores - uma compreensão curricular e; Formação em exercício de professores - o mestrado profissional. Ou seja, mesmo não assumindo a formação de professores como grande foco temático, esse eixo de intervenção faz-se presente em um dos seus núcleos estruturantes.

Outro exemplo bastante interessante é o da Pontifícia Universidade Católica de São Paulo (PUC - SP). O Mestrado Profissional em Formação de Formadores (Formep) foi aprovado pela Capes em dezembro de 2012, e começou a funcionar em agosto de 2013. A criação do MP com foco na formação de formadores de professores emergiu da compreensão acerca do papel fundamental que esse profissional ocupa na efetivação do trabalho pedagógico nas escolas e na qualidade das atividades desenvolvidas pelos professores e alunos, particularmente na função de coordenação pedagógica, 
contribuindo na implementação do projeto político-pedagógico, formação contínua dos docentes e bom andamento das atividades educativas. Estruturado em duas linhas de pesquisa - a saber, formação profissional do formador e intervenções avaliativas na sala de aula -, a proposta do Formep busca criar condições para o desenvolvimento profissional desse sujeito, dando-lhe oportunidade de identificar problemas e soluções da prática pedagógica dos docentes. Desse modo, a proposta de trabalho final dos mestrandos volta-se à prática profissional com a contribuição de tutores, que vêm a ser doutorandos de programas de pós-graduação da PUC-SP. Estes se propõem a contribuir com os mestrandos na problematização do seu objeto de estudo, da elaboração e revisão dos textos (GATTI et alii, op. cit).

Essas experiências põem em destaque o papel promissor dos mestrados profissionais em educação relativamente à articulação com a educação básica e, particularmente, com a formação dos profissionais da educação. Mais recentemente, com a instituição dos Doutorados Profissionais (DP), abre-se uma nova janela de oportunidades para esse trabalho de formação do magistério.

\section{A Emergência dos Doutorados Profissionais}

Embora sem um debate aprofundado sobre seu conteúdo e sua finalidade, o fato é que, em 2017, foi instituído, no âmbito da pós-graduação stricto sensu, a modalidade de DP, por meio da Portaria n 389, de 23/3/2017, do Ministério da Educação. Os doutorados profissionais teriam os seguintes objetivos: a) capacitar profissionais qualificados para o exercício da prática profissional avançada e transformadora de procedimentos; b) transferir conhecimento para a sociedade, visando demandas específicas e de arranjos produtivos com vistas ao desenvolvimento; c) promover a articulação integrada da formação profissional com instituições de naturezas diversas, com vistas à eficácia e eficiência das organizações e; d) contribuir para o incremento da competitividade e da produtividade de empresas públicas e privadas.

Ainda segundo a portaria supramencionada, o perfil do doutor profissional deve se caracterizar pela autonomia, geração de conhecimento e de capacidade de produção e transferência de tecnologias inovadoras para soluções inéditas de problemas de alta complexidade em seu campo de atuação. Nesse sentido, a proposta curricular deverá atender às necessidades da sociedade, em conexão com o foco do programa, mantendo-se a qualidade e o rigor esperados de um programa de doutorado. Deve estar atenta ao caráter transformador da realidade social, do processo produtivo e do estado da técnica vinculado à área. Os DPs devem articular novos paradigmas na atuação do docente e demais profissionais da educação a partir do estímulo e das experiências inovadoras numa perspectiva autônoma e emancipadora. 
Portanto, no campo da Educação, a inclusão dos DPs amplia os espaços para formação de pessoal altamente qualificado para atuar na educação básica e para implementação de políticas educacionais. A introdução do DP abre novos horizontes no sentido de atender, no mais alto nível, às necessidades da educação brasileira. Por outro lado, é importante que o DP não acabe desconfigurando o atual mestrado profissional, que é, por natureza, terminal, preparando seus egressos para atividades no campo da educação básica.

\section{Considerações Finais}

O sistema de pós-graduação do Brasil, estruturado a partir dos anos de 1960, com seu modelo de fomento, avaliação, acompanhamento e envolvimento da comunidade científica, alcançou elevado prestígio nacional e internacional (ALVES, OLIVEIRA, 2014, p. 372). Amparado por métricas auditáveis e que, por vezes, geram críticas duras de membros da comunidade científica, o modelo tem assegurado uma base estável de avaliação dos cursos de pós-graduação stricto sensu.

Os programas profissionais, por sua vez, encontraram maior resistência quanto à sua aceitação pelo Sistema Nacional de Pós-Graduação. Nos dias atuais, todavia, os mestrados profissionais já foram devidamente incorporados na dinâmica avaliativa. Os doutorados profissionais, por se encontrarem ainda em instalação, precisam de um tempo para a averiguação de sua efetividade. Há um longo caminho a ser percorrido, e o acompanhamento desses cursos deve se dar com maior intensidade.

Pode-se adiantar, no entanto, que o campo de atuação dos programas profissionais na esfera da formação docente é bastante promissor, não apenas pela quantidade de docentes sem pós-graduação no Brasil, mas, sobretudo, pelo papel que podem representar na melhoria da educação básica a partir de estudos e pesquisas que foquem na solução de problemas do cotidiano escolar. Contudo a construção das identidades dos programas profissionais da área de Educação ainda está em processo. Esse é um dos grandes desafios da atualidade.

A expansão de mestrados profissionais em educação tem contribuído para a redução de assimetrias na oferta de pós-graduação no país e para o desenvolvimento de conhecimentos teóricos e técnicos necessários à solução de problemas concretos enfrentados pelos docentes em sala de aula. Assim, esses programas devem lidar com a capacitação de recursos humanos de alto nível para atuar, sobretudo na educação básica, seja como docentes ou gestores, seja como especialistas que dão suporte pedagógico ao trabalho docente, tais como desenvolvimento e aplicação de currículos, sistema de avaliação, material didático, novas tecnologias e atividades afins. Esse parece ser um bom caminho! 


\section{Notas}

1 Correspondente, no Brasil, ao ensino fundamental com ingresso obrigatório aos seis anos de idade e conclusão estimada aos 14

2 Doravante denominados de programas profissionais.

3 A referência à atividade em sala de aula não é fortuita. Outas práticas educativas, sobretudo aquelas fora do contexto escolar, podem ocorrer sem a necessária recorrência às técnicas pedagógicas e aos seus fundamentos teóricos.

4 A CAPES foi criada em 1951, ainda com a denominação de Campanha Nacional de Aperfeiçoamento de Pessoal de Nível Superior, pelo Decreto n 29.741, com o objetivo de "assegurar a existência de pessoal especializado em quantidade e qualidade suficientes para atender às necessidades dos empreendimentos públicos e privados que visam ao desenvolvimento do país".

5 Esse decreto foi revogado pelo Decreto n 8.752, de 9 de maio de 2016. O novo decreto dispõe sobre a Política Nacional de Formação dos Profissionais da Educação Básica.

6 A íntegra do Parecer pode ser acessada em http://www.scielo.br/pdf/rbedu/n30/a14n30.pdf.

7 As razões pela demora da área de Educação no sentido de implementar cursos profissionais são abordadas por Verhine (2006).

8 A CAPES adota o sistema de colégios, os quais agregam as 49 áreas de avaliação. Os colégios são: ciências da vida, humanidades e ciências exatas, tecnológicas e multidisciplinar. A área de educação está abrigada no colégio de humanidades.

9 Disponível em https://www.capes.gov.br/images/novo_portal/documentos/DAV/avaliacao/10062019_Produ\%C3\%A7\%C3\%A30-T\%C3\%A9cnica.pdf

10 Note-se que esses cursos não compõem a área de Educação da CAPES, e sim a área de Ensino.

\section{Referências Bibliográficas}

Alves, M. F.; Oliveira, J. F. (2014). Pós-Graduação no Brasil: do regime militar aos dias atuais. RBPAE, 2 (30), 351-376.

Calderón, A. I. et al. (2019). Doutorado Profissional em Educação: tendências em universidades de classe mundial contextualizadas nos rankings acadêmicos internacionais. Práxis Educativa, 14, 1, 138-162. [Disponível em: http://www.revistas2.uepg.br/index.php/praxiseducativa, consultado em 12/06/2019].

Campos, M. A. T.; Guérios, E. (2017). Mestrado Profissional em Educação: reflexões acerca de uma experiência de formação à luz da autonomia e da profissionalidade docente. Educar em Revista, $63,35-51$.

Brasil. (2016). Decreto $n^{\circ}$ 8.752, de 9 de maio de 2016. Dispõe sobre a Política Nacional de Formação dos Profissionais da Educação Básica. Brasília, DF. Recuperado em 12 de setembro de 2018, de http://www.planalto.gov.br/ccivil_03/_Ato2015-2018/2016/Decreto/D8752.htm

Brasil. (2019). Documento de Área - Educação. Brasília, DF, recuperado em 10 de junho de 2019, de < http://capes.gov.br/images/educacao_doc_area_2.pdf>.

Fialho, N. H.; Hetkowski, T. M. (2017). Mestrados Profissionais em Educação: novas perspectivas da pós-graduação no cenário brasileiro. Educar em Revista, 63, 19-34.

Gatti, B. et alii (2019). Novos cenários da formação de professores. Brasília, DF/ UNESCO. [Disponível em: $\quad$ https://unesdoc.unesco.org/ark:/48223/pf0000367919?posInSet=2\&queryld=c605a90897da-4777-a996-b3532872f9a1, consultado em 12/06/2019] 
Nobre, L. N.; Freitas, R. R. (2017). A evolução da pós-graduação no Brasil: histórico, políticas e avaliação. Brazilian Journal of Production Engineering, 3 (2), 26-39. [Disponível em http://periodicos.ufes.br/ BJPE. Acesso em 19.07.2019, consultado 12/06/2019]

Oliveira, B. J. de \& Zaidan, S. (2018). A produção de conhecimento aplicado como foco dos mestrados profissionais. In: Guimarães, S.; Gonçalves Neto, W. (Org.). Mestrado Profissional: implicações para a educação básica (pp. 41-57). Campinas, SP: Editora Alínea.

Parecer CFE no 977/1965 (2005). Revista Brasileira de Educação, 30, 162-176.

Capes. (1998). Portaria n. 080, de 16 de dezembro de 1998. Dispõe sobre o reconhecimento dos mestrados profissionais e dá outras providências. Brasília, DF, recuperado em 04 de agosto de 2019, de https://www.capes.gov.br/images/stories/download/legislacao/Portaria_CAPES_080_1998.pdf.

Capes. (2017). Portaria n. 389, de 23 de março de 2017. Dispõe sobre o mestrado e o doutorado profissional no âmbito da pós-graduação stricto sensu. Brasília, DF. Recuperado em 19 de abril de 2018, de http://www.in.gov.br/materia/-/asset_publisher/KujrwOTZC2Mb/content/id/20482828/ do1-2017-03-24-portaria-no-389-de-23-de-marco-de-2017-20482789

Capes. (1995). Portaria n. 47, de 17 de outubro de 1995. Brasília, DF, recuperado em 04 de agosto de 2019, de http://www.foprof.org.br/documentos/portaria-no-47-17-outubro-1995.pdf

Capes. (2009). Portaria Normativa n. 17, de 28 de dezembro de 2009. Dispõe sobre o mestrado profissional no âmbito da Fundação Coordenação de Aperfeiçoamento de Pessoal de Nível Superior (CAPES). Brasília, DF. Recuperado em 05 de agosto de 2019, de https://capes.gov.br/images/ stories/download/legislacao/16112018_PortariaNormativa_n\%C2\%BA17.pdf

Capes. (2009). Portaria Normativa n. 7, de 22 de junho 2009. Dispõe sobre o mestrado profissional no âmbito da Fundação Coordenação de Aperfeiçoamento de Pessoal de Nível Superior (CAPES). Brasília, DF. Recuperado em 12 de setembro de 2018, de https://www.capes.gov.br/images/stories/ download/legislacao/Revogada-Portaria-Normativa-n_7-22-de-junho-2009-Mestrado-Profissional. pdf

Capes. (2019). Relatório Grupo de Trabalho Produção Técnica. Brasília, DF, recuperado em 04 de agosto de 2019, de https://www.capes.gov.br/images/novo_portal/documentos/DAV/ avaliacao/10062019_Produ\%C3\%A7\%C3\%A30-T\%C3\%A9cnica.pdf

Soares, J. F. (2005). Qualidade e equidade na educação básica brasileira: fatos e possibilidades. In: Brock, c.; Schwartzman, S. (Org.). Os desafios da educação no Brasil (pp. 88-113). Rio de Janeiro: Nova Fronteira.

UNESCO-UIS. (2016). The World Needs Almost 69 Million New Teachers To Reach the 2030 Education Goals. Montreal (UIS fact sheet, 39). <http://www.uis. unesco.org/Education/Documents/FS39teachers-2016-en.pdf>. Acesso em: 19 jun. 2019.

Verhine, R. E. (2006). As recentes políticas da Capes e suas implicações para a Área de Educação. In: Monteiro, F.; Muller, M. (Org.) Educação na interface da relação estado/sociedade (pp. 23-34). Cuiabá, MT: EDUMAT-FAPEMAT. 


\section{Luiz de Sousa Junior} PPGE/MPPGAV/UFPB

Coordenador dos Programas Profissionais da área de Educação da Coordenação de Aperfeiçoamento de Pessoal de Nível Superior (CAPES)

E-mail: luizsjunior@gmail.com ORCID: 0000-0002-5646-941X

Robert Evan Verhine PPGE/UFBA

Coordenador da Área de Educação da Coordenação de Aperfeiçoamento

de Pessoal de Nível Superior (CAPES)

E-mail.: verhine@ufba.br

ORCID: 0000-0002-5157-3680

Correspondência:

Luiz de Sousa Junior

Universidade Federal da Paraíba - Campus I

Cidade Universitária - CEP 58051-900 - João Pessoa-PB-Brasil

Data de submissão: Setembro de 2019

Data de avaliação: Dezembro de 2019

Data de publicação: Novembro 2020 